\title{
The Heart of the Locomotive
}

\section{The Reason for the "Grasshopper" Valve Motions Seen on Modern Locomotives}

By C. H. Claudy

THE human heart controls the circulation of the T life blood. The valves of a steam engine control the circulation of its life blood-steam. If the valve acts well, the engine is prompt, economical, precise,

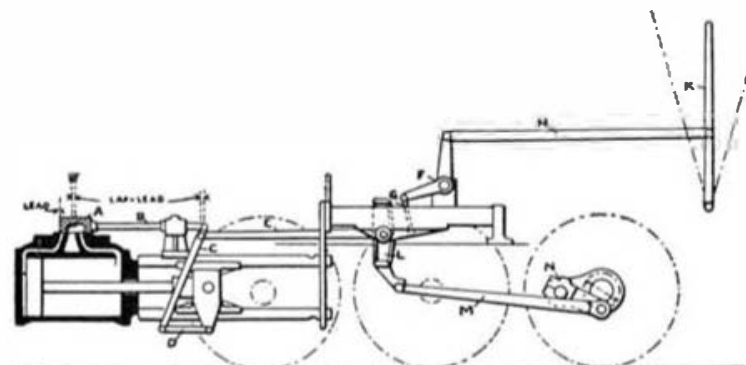

Walschaerts valve gear diagram.

From the return crank $N$ the connecting rod $M$ works
the link $L$ in which the block at the end of the rod $E$ slides. 'This block is raised and lowered by means of the reverse lever $K$, and the rods $H$ and $F$ and the joint $G$. The valve $A$ and the valve rod $B$ are worked jointly by the return crank motion and motion obtained from the cross-head through the rods $D$ and $C$. The travel of the valve $A$ is governed by the postton or the block in the the tained through the motion of the cross-bead.

powerful. If the valve is faulty, the engine lacks power, limps on its way, and allows its energy to run to waste. At first glance it might not seem to the casual reader that there was anything very difficult in the making of a proper valve motion. But the locomotive designer has much to contend with that the stationary engineer has not. When it is considered that with an engine running at speed, the valve opens its ports or steam ways by less than half an inch, that a valve may operate ten times in a second, that a whole valve motion weighs from one to more than two tons, and that the least change in its exact working will affect both speed and power and coal consumption, and that it must work equally well in a yard at low speed or at high speed upon a rough track, then its making does not seem so simple.

A few years ago constant travelers noted, often with curiosity, that the trim American engine with which they had long been familiar had grown a new set of rods and eranks. The general public asked what this "grasshopper" was which had suddenly begun to appear among the familar working They called it "grasshopper", because, in motion, this valve gear, the real name of which is the Walschaerts, from its inventor, has ungainly rods and sharp-angled joints in operation.

It is more familiar now, as railroad after railroad has specified it on new equipment, and replaced the older or Stephenson valve motion or gear with this foreign invention. But its working and the reason for the change remain a sealed mystery to the man on the street, simple as these real reasons actually are.

It may be something of a shock to know that it is not a new valve motion, this gear with the peculiar name, and that for more than half a century it has builders. motive really is and does. the used steam out of the cylinder. schaerts gear. been common in Europe. It seems strange that a country which has led the world in railroading should follow so long after Europe in this vital matter.

But the reason is not far to seek. Most foreign engines are "inside connected," that is, their cranks, pistons, cross-heads all work between the wheels and not on the outside of them, as with us. Hence, there was less space between the wheels for extra mechanism and a valve gear which could be applied outside the wheels had a powerful argument in its favor.

That is one of the reasons why. American locomotives, particularly the larger ones, now have these strange steel "grasshoppers" on either side. The space between our wheels, too, is getting valuable. The familiar four eccentrics take up room. That room is needed for bracing, with the increase of weight and size of boilers. Hence, an outside gear made its appeal to American

But matters of space and convenience are not all the arguments which have displaced the familiar "Stephenson link" gear with the Belgian machine shop foreman's peculiar device. To understand these other reasons is to understand something of what the heart of a loco-

Everyone knows that steam makes an engine go by being allowed to enter a cylinder in which is a piston. The pressure on the steam pushes the piston, which is connected by means of rods to the wheels, and so they turn. Most people will understand without being told that the steam is allowed to enter first one end of the cylinder and then the other, so that the piston is first pushed forward and then pushed back again.

There must also, of course, be some way of letting

The letting the steam in and out again is the work

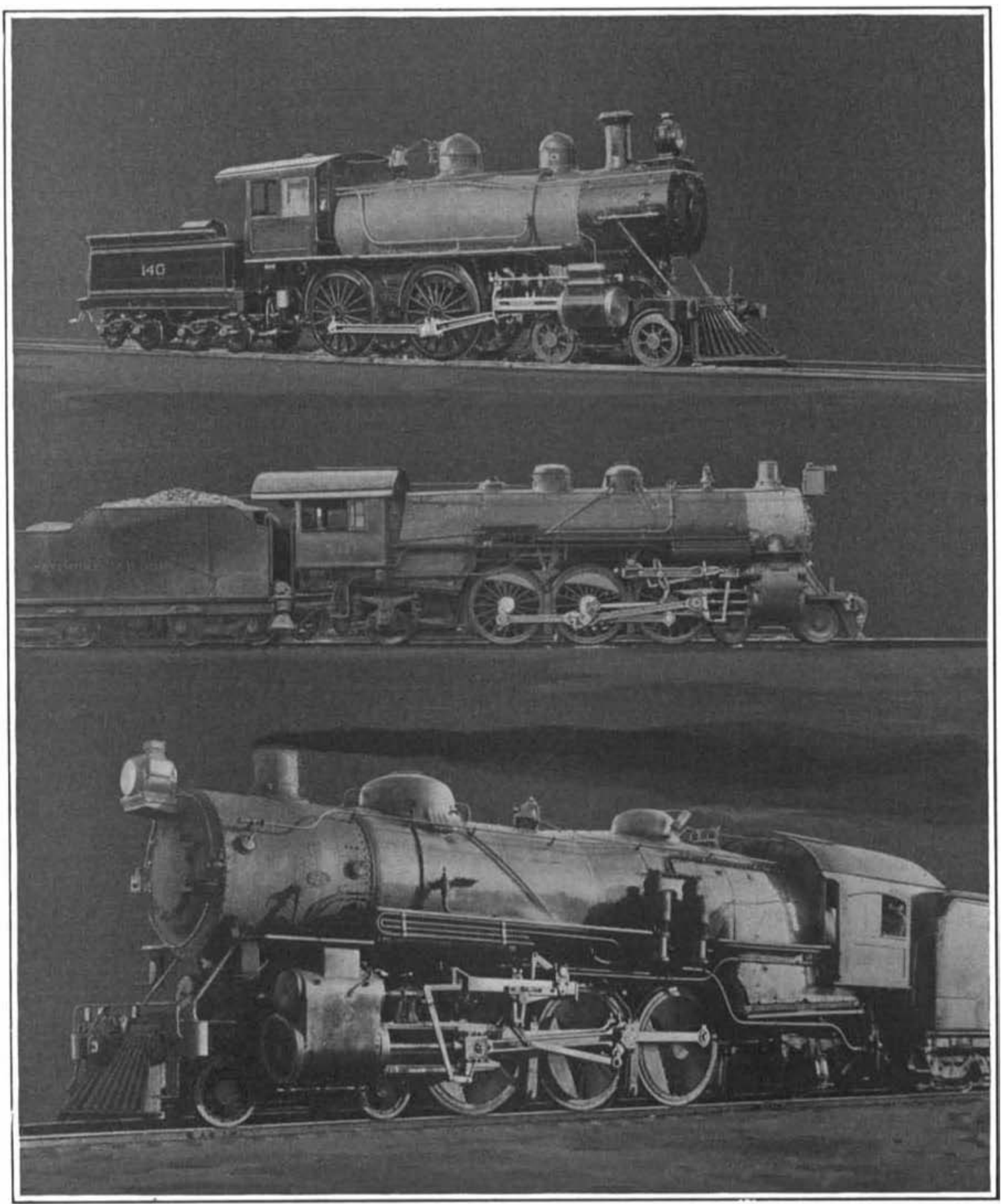

Typical American express locomotives. Upper view an "American" or 4-4-0 model, with Stephenson valve gear. Tha other views show opposite sides of the "Pacific" models (4-6.2) fitted with the Wal- of the valve. In the cylinder are two admission ports, through which steam flows from the steam chest into which it comes from the boiler. The exhaust steam comes out through these same ports, but not back into

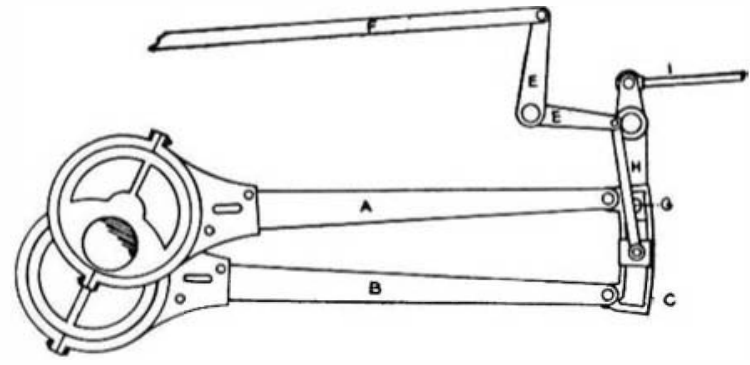

Stephenson valve gear.

Two eccentrics $A$ and $B$ are connected with a link $O$, which can be raised and lowered by means of the link the reverse lever in the cab. The block $\theta$ is fixed to the end of the rocking arm $H$ from the top of which the valve rod $I$ leads to the valve in the steam chest. The travel of the valve is under the control of the engineer, by means of the reverse lever, but the lead of the valve effect as slightly increasing or decreasing the the same angular advance of the eccentrics. The lead to greater, in forward motion, the more the link is raised toward the central or neutral position. Fixtreme cut ofi, then, gives extreme lead, which is not always desirable. This feature is obviated in the Walschaerts motion, in which the link is pivoted and the block raised, lead being obtained not

the steam chest, of course. Exhaust steam travel through the steam port not being used for letting steam smoke stack, becau valve directs it, forces it to take that course. The valve, which, in its simplest form, is like the letter $D$ laid on its side, and its upright taken away, covers first one port and the exhaust way, then the other port and the exhaust way. The valve works in the steam chest or valve chest, and is constantly surrounded by steam, so that the life blood of the engine is always pressing for admission to the cylinders.

The valve in the Stephenson gear is worked forward and backward by means of eccentrics on the driving axle. If an engine had ouly to go forward, one eccentric would be enough. But because an engine must go either forward or backward, there are two eccentrics for each "slide valve." These are connected by rods to what is known as the "link," a curved, oblong frame, and in the link is a block, connected to the valve rod. The connection is $\mathrm{made}$ through what is known as a rocker arm, but it is not important in understanding the principle or function of the valve. When the link is down, one eccentric works the valve. When the link, by means of the reversing lever in the e ngin e er's cab, is pulled $u p$, the other eccentric works the valve and the engines goes the other way.

The theoretical position for the eccentric is at 90 degrees to the crank, so that, when the piston is at the exact end of its stroke

(Oonoluded on pege 86.) 


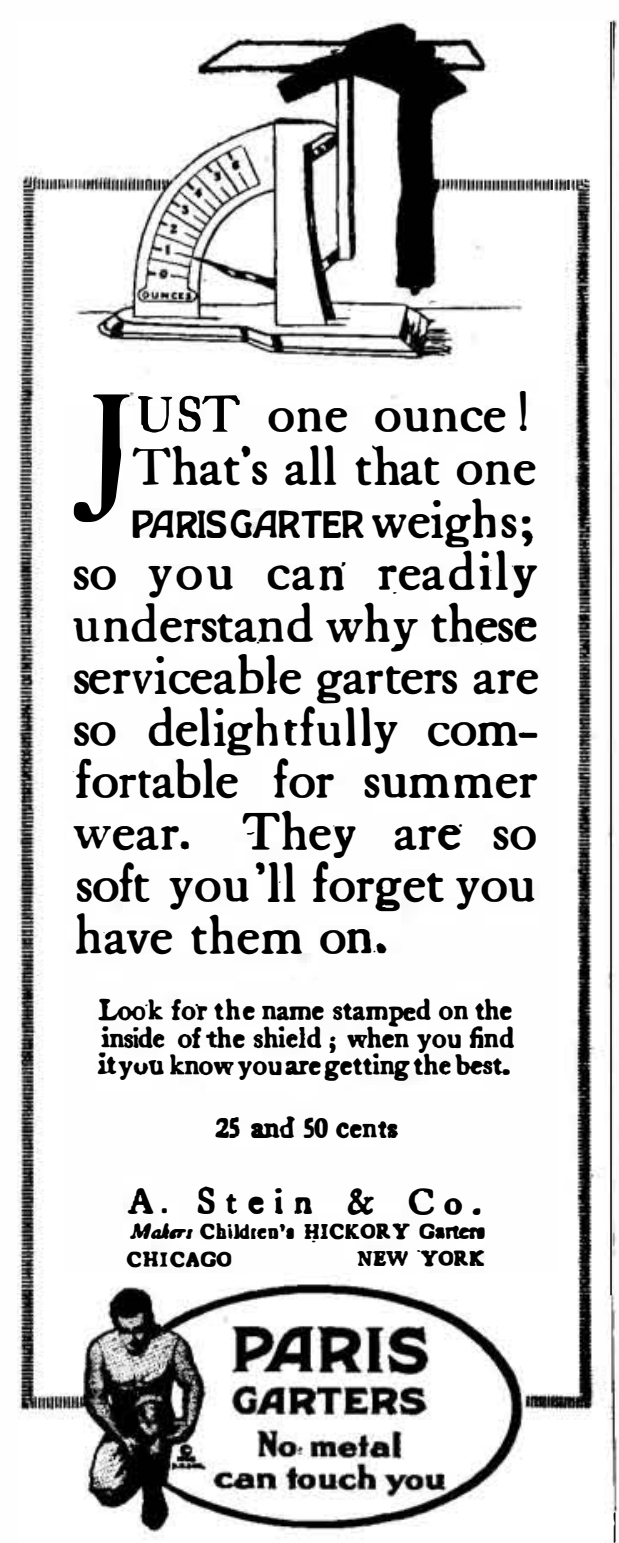

Who Can Use This New Product With Unusual Physical Properties?

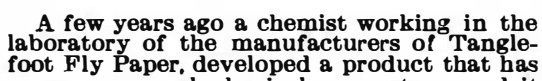

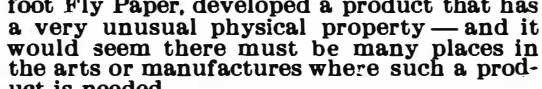
Its remarkable physical property is that it
will remain sticky or viscid when fully exposed
to the wind sun, rain eic from ten to twent will remain sticky or viscid when fully exposed
to the wind sun. rain, etc , from ten to twenty
times as lono as any other known substance. Its long continued pliability should make it
valuable to fll cracks in cement or any valuable timbers exposed to the weather, such as piles.
Also for making riveted iron work tight as in
boats, tanks, etc., it ishould prove useful, and
in difficult problems of waterproofing. The substance has been named Tree Tangle-
foot because it has found quite an extensive vent the ascent of injurious caterpillars or
other insects. particularly gypsy and browntail moths, tussock moths, cankerworms, fal
web-worms, ants, etc. It is also the best
possible application after pruning or tree
surgery. It will waterproof a wound or
eventhe croter of on old tree when nothing surgery. It will waterproof a wound or
even the crotech of an old tree when nothing
else will do it. The manufacturers invite correspondence
from anyone who might be interested.

THE O. \& W. THUM CO., Grand Rapids, Mic

Valuable Books of Instructionand Reference

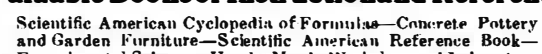
MUNN \& CO.. Inc., Pablishers, Woolworth Bids., New Yort

WHY WELD

When you can do better work in onefourth the time, at one-fourth the price,
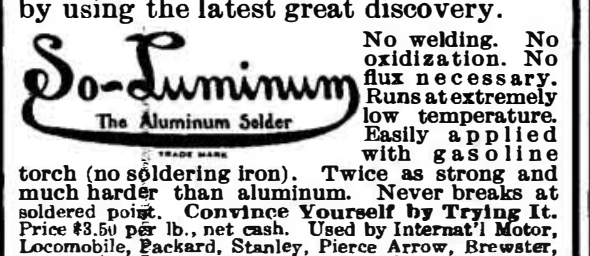

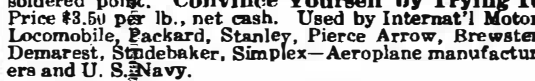

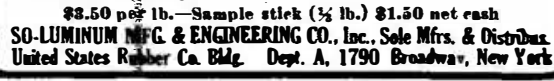

LEARN TO BE A WATCHMAKER

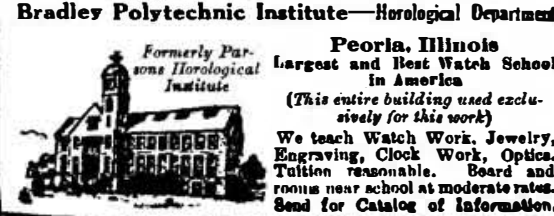

\section{The Deart of the Lowedtre} (Oonoluded rrom ocos 78 ,

the ralve will be in the eract middle of

"Booted up," has been the aif and end of thoueands of inventors.

The peculiarity of the Walschaerts gear its stroke. The least motion forward or is found in the fact that it has only one admit steam to one end or the other of turn crank" from the main crank on the the cylinder. Such a construction would main driver, and that this one eccentric begin to admit steam to the cylinder only or return crank does all the work of the after the piston had started on its stroke. valve gear as far as determining the But practically this will not work out. It travel of the valve is concerned. It opis found that steam should be admitted to erates a rocking link which does not move the cylinder before the piston finishes one up or down, and in which the block, constroke in one direction and begins a stroke nected to the valve, is moved up and down in the other. It must do this for several by the reversing gear. The "lead" is reasons. One is to furnish a cushion of given to the valve by bringing in a mosteam, a pressure in the cylinder, to help tion obtained from the "cross-head," take up the jar and shock of stopping the "lead" which remains constant, regardless piston and piston head, before it starts in of the position of the block in the link. the reverse direction. Another is to allow Hence, the engineer can "hook her up" all the piston to have something to compress, he wants, but the "lead" of the valve reso that when the valve port opens full, mains constant.

the cylinder pressure and the boiler press- But the advantages of the Walschaerts ure are already about the same, and the valve gear are not confined to a mere mattiny interval of time which would other- ter of constant "lead." Its accessibility wise be necessary to bring the cylinder commends it highly to engineers who must pressure up is saved.

have the care and oiling and inspection There are other reasons, but these of it. Because it does not take up valwill suffice. The "angular advance," or uable under-boiler room it commends itamount by which the eccentric is in front self to the designer, who also finds in its of its theoretical position, gives the valve much lighter weight a great blessing. The what is known as its "lead." The "lead" Walschaerts gear transmits its motion of a valve makes everything which occurs from driving wheel and cross-head to in the cylinder, that is, admission of steam, valve in almost a straight line, which cut off of steam, expansion of steam, ex- avoids the errors of distortion found somehaust of steam, admission of steam to the times in the Stephenson gear, which gain other end, cut off of that steam, etc., occur its motions from eccentrics between the earlier than would otherwise be the case. wheels, and transmits it to a valve conBut the matter is complicated by the ne- siderably to one side. The Stephenson cessity of what is known as "lap" on the "link," acting under the forces from two valve, that is, the extra length or face of eccentrics, moves through a wide angle. the valve which permits early "cut off" A wedging action on the block takes place without too early pre-admission of steam at high speeds, and this, together with the to the cylinder.

difficulty of oiling large eccentrics prop" ting off of steam. The shorter the travel times collect "lost motion." Lost motion of the piston during the time steam is in a valve gear is about as welcome as a coming in, the less steam is used, of cat at a mouse party, and does about as
course, and the more economy in coal. much damage in the long run. Finally, Early "cut off" allows the steam to ex- the Walschaerts gear is said by maste pand and use this expansive force which mechanics to be more "foolproof" than the is wasted when the engine is running in ordinary gear. There is less opportunity full gear without much "cut off."

to "tinker" with it, to experiment in two ec- changes in eccentric positions, and its cost centrics. If a valve had no lap, and the of maintenance is less than that of th eccentric was at exactly 90 degrees with older, heavier, clumsier mechanism. the crank, so that the valve had no lead, It may be of interest to remember that one eccentric would do for either forward Egide Walschaerts, to whom the railway or backward motion, changing from one world owes so much, died near Brussels to the other by a simple link motion. But, fourteen years ago, at the ripe age of in practice, valves do have and must have eighty-one. It is true that he was first a both "lap" and "lead," and so two eccen- mechanic, lived a mechanic and died a trics are necessary (at least in the fa- mechanic, that his position in life was almiliar Stephenson motion), one arranged ways that of a workman, a foreman in or set for forward motion and one for the workshops. But Walschaerts was a foreman from choice, not necessity. He motion builded better than they knew tigations tape, thought reports and inveswhen they designed the "link" and the wanted nothing more than a blue print in two eccentrics. For it was found that the his hand, a shop to work in, and som use of the reversing lever, which raises engines to work on. As a boy, he had the link through its entire throw, was not been fascinated by the then brand new confined to reversing the engine. When idea of railroading. Born at Malines, in the link is raised exactly half way, each Belgium, the connecting of that town by eccentric has an opposite effect upon it, railroad with Brussels in 1835 determine and the valve has but a slight movement. his career. Though he worked on im The more the link is raised or lowered provements in steam vessels, and stationbeyond this point, the greater becomes the ary as well as marine engines, it was the travel of the valve until it is working in locomotive which he loved and on which full gear.

he spent most of his time. He met with The engineer thus has at his hand a great appreciation from the State railmethod of increasing or decreasing the ways of his country; later all Europe travel of the valve, which, of course, grad- adopted his valve gear, and now the ually increases or decreases the size of United States is using it as fast as it can the effective steam opening into the cylin- be applied.

der. Because the economical use of steam So it is that a Belgian "grasshopper" is demands that its expansive force be util- to be found on most modern United States ized, this is of great service to the engi- engines, and the traveler who casts neer. The familiar expression, met with curious glance at the queer rods and even in railroad fiction, of "hooking her joints which give a constant "lead" up," comes from the use of the reversing matter what the "hook up" or cut off, lever to shorten the travel of the valve, which make a light mechanism do the and this gives the steam a chance to use work of a heavy, and which tends to its expansive power in the cylinder.

But, because of questions of space under trength in the engine by giving space for of infinite length; and with the short ec- tent to wear overalls all his life, though centric rods, the familiar "hooking up" he had the capacity to become a wealth operation gradually increases the "lead" business man, because of his love for the of the valve, as its travel is shortened. horse of the iron rail, and his neverToo much "lead" is as bad as too little- ending investigations into the mechanism some engineers say worse. And, for this the mathematics and the physics of that reason, a valve gear which should never greatest triumph of steel and iron, the change the "lead" no matter how it was locomotive.
LEGAL NOTICES

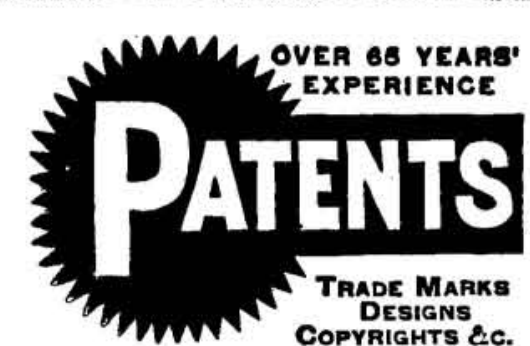

INVENTORS are invited to communicate
with Munn \& Co. 233 B roadway New York.
or 625 F Street Washington D.C. in regard to securing valid patent protection for their
lnventions. Trade -Marks and ropyrights
registered. Design Patents and Foreign Pat-

entes secured

A Free Opinion as to the probable patent
ability of an invention will be readily given
to any inventor furnishing us with a mode

or sketch a nd a briee description of the
device in question. All communications are
strictly conflientia. Our Ha nd. B oo on on
Patents will be sent free on request.

Ours is the OIdest agej cy por securing
patents; it was. established over sixty-five
years ago.

All patents secured through us are de-
scribed without cost to pat nt $^{2} \mathrm{e}$ in the
Scientific American.

MUNN \& CO.

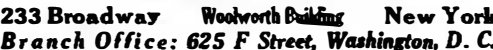

Classified Advertisements

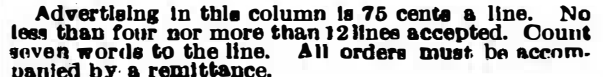

CAPITALISTS, MIFRS. \& BUILDERS

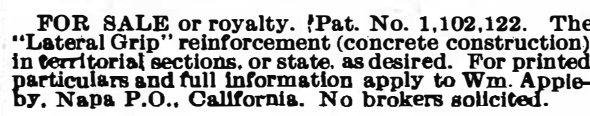

GETP WANTED

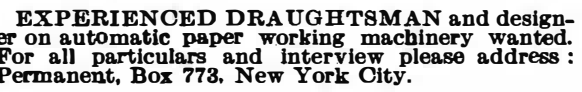

FOR SALE

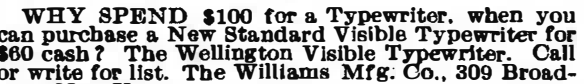

PATENT FOR SALE

STOVE that heats 3 or 4 rooms - that can bake in
wo places. Will heat water with same gas without

waste. No other stove so ec onomlcall see 1tem on
page 85. D.Carjulo, 2943 White Plains Rd..New York.

I N Q U I R I E S

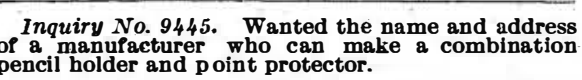
Inpuiry No. 9446 . Wanted the name and address

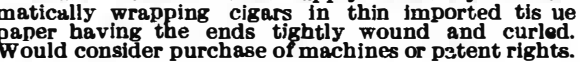

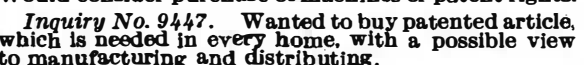

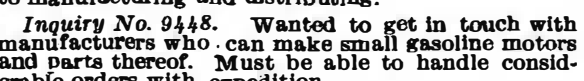

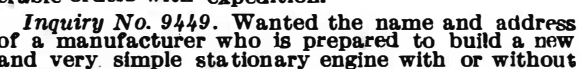
gas producer. Inquiry No. 9450. Wanted the name and address
of a manufacturer who can build a likht simple mo-
tor for light automobiles and for portable farm work Inquiry No. $945 I$. Wanted the name and address of
a manufacturer of machinery for making egg albumen.

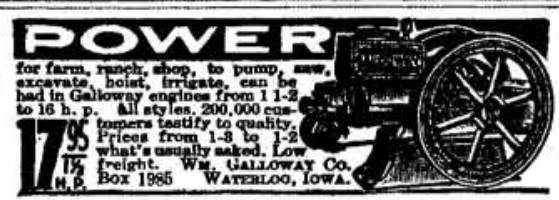

(I)

\section{The Proper}

\section{Private School}

for your children is perhaps the
most important choice you have to make. You need the best guide in existence and that undoubtedly
you will find every month in the

Educational Directory Harper's Magazine

for it is in Harper's Magazine that you private and preparatory schools and colleges than in any other publica-
tion-the widest, the best, and the most dependable selectio 


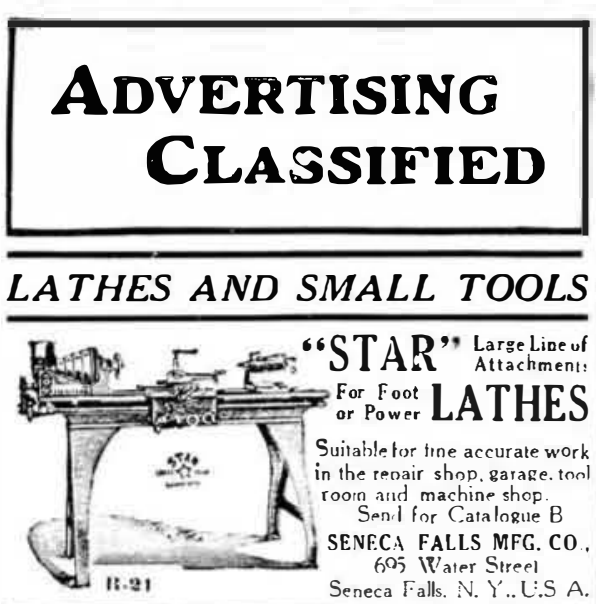

For Gunsmiths, Tool Makers, Experimental \& Repair Work, etc.

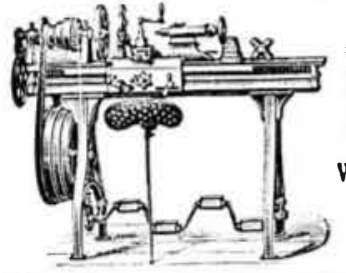

GROBET SWISS FILES

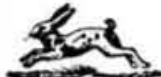

MONTGOMERY \& CO

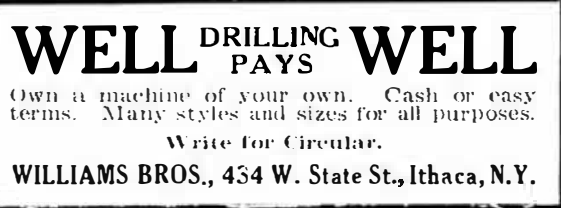

COMFORT SELF-HEATING
SMOOT HING IRON

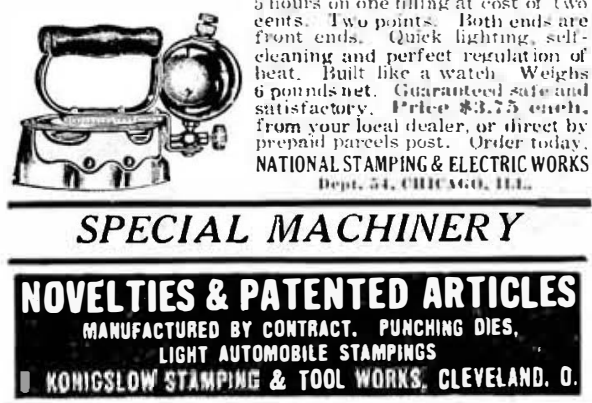

Models and Experimental Work INVENTIONS DEVELOPED

E. V. BAILLARD CO., 24 Frankifort St., N. Y.

DIES AND TOOLS

B.A. D. F. . C.. Inc., 110.120 S. Church St. Schenectady, N.

MASON'S NEW PAT. WHIP HOISTS

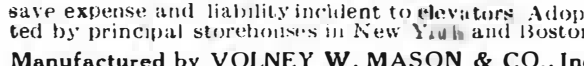
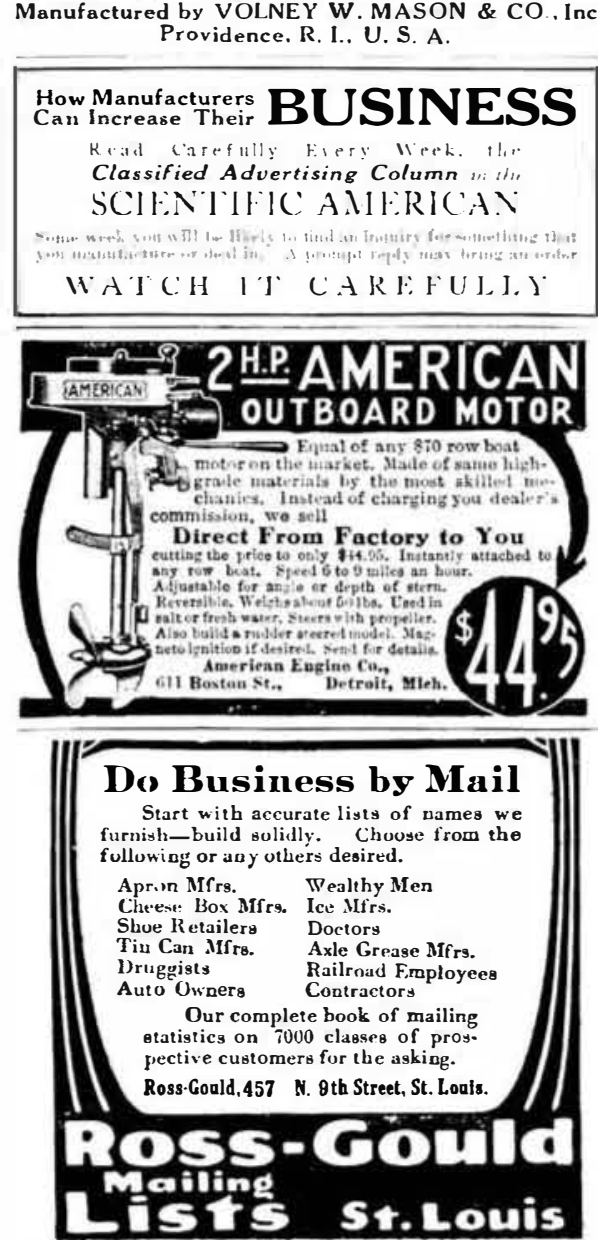

The Thermaphone

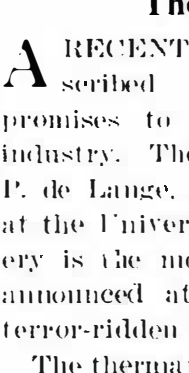

aiving

mall they may easily he carried in the ordinary watch. The cost of manu(n)

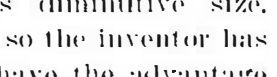




\section{Interlocking Steel Construction}

A SYSTEM of fastening steel beams together without the use of rivets was recently tested at Colum bia University with results that were surprisingly favorable. The webs and flanges of the beams were slotted or recessed and then they were interlocked in such a manner as to reinforce one another. The purpose of this construction is to dispense with the cost pose of this construction is to dispe

In the accompanying engraving, Fig. 1 shows how a floor beam $E$ may be secured to a column $D$, a slot $F$ being cut in the column to receive the beam. A pair of clips $G$ flt snugly over the upper flanges of the beam $E$ and between the flanges of the column $t$, leaving a slot between them to receive column $H$.

Fig. 2 shows the construction of a bent such as would be used in a mine. A little study will show how the legs $A$ flt into recesses in the beam $B$ and are held from sliding out by $B$ and $C$. The last are ftted on the on the beam $B$ before it is slipped into place on the members $A$. The roof beams interlock with the clips $C$. The legs $A$ are anchored in baseblocks as illustrated. Of course, the details of the joints will vary to different structures.

The structure tested at Columbia University was such as would be used on a four-tube subway.

Wait's interlocking steel is constructed by various ways of recessing the web and flanges of both the

I and $H$ beam to the necessary form of usage to which it is to be adapted; in so doing each joint reinforces itself, whether for subway, bridges or mining, and erec tions of buildings. The same basic principle is applie in each different construction, but necessitating various forms of locks independent of beams to unite the various angles or lines in construction.

The test of May 29th at Columbia University was a form for subway construction of a four-tube subway.

The test was a great surprise to all that were present. This section was formed of 4-inch H-beam column and 6-inch I-beam girders. The second story was interlocked by one set of lock sections for continuing column locke I-beam indicated an equal stress on the supports The I-beam indicated an equal stress on thr of the web of the upper I-beam. At 153,000 the stress was discontinued so as not to destroy the beam totally. The lock or the columns did not show any failure and remained perfectly true in form. The damaged sections could be replaced in flve minutes. The tappin of a 4-pound hammer was all that was necessary to remove them. A 6-inch I-beam is supposed to fail comremove them. A 6-inch I-beam is supposed to fail com-
pletely at 100,000 pounds where the flanges are not supported. As these were not supported, the 53,000 pounds of extra pressure indicated must have been distributed throughont the out-members constituting the complete unit. This would indicate that a construction of interlocking steel is one third stronger than where rivets are used.

\section{A Submarine Catcher}

THE illustrations show a new method and apparatus 1 for catching submarines, differing in many features from those previously described. Comparatively narrow channels to harbors are usually protected from submarines by mooring strong steel nets across the channel from shore to shore. Such protection, however, is not

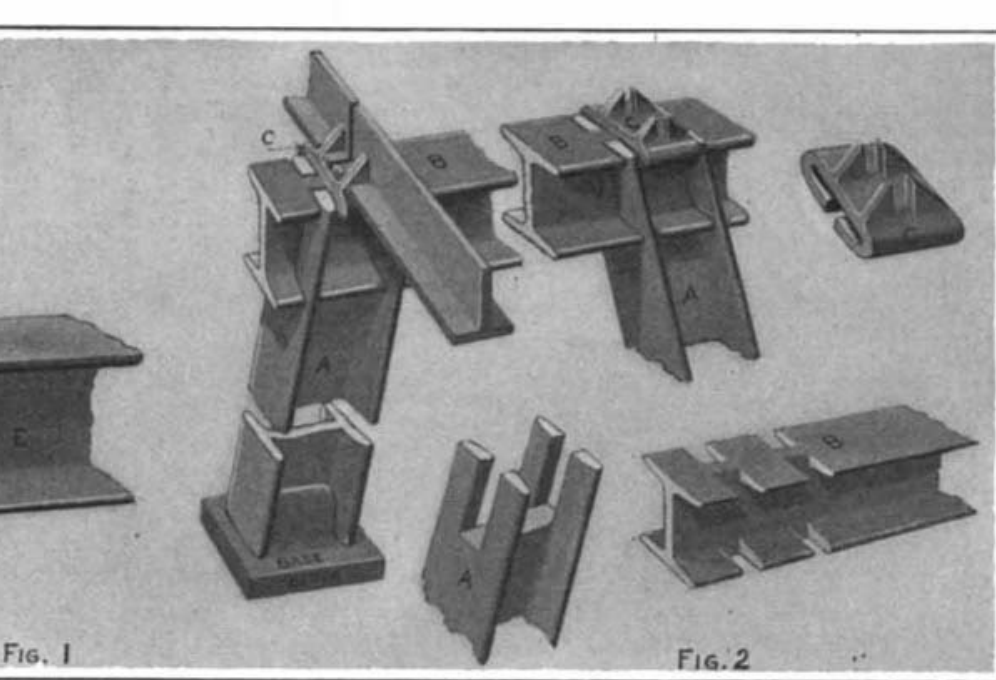

System of steel construction that dispenses with rivets.

so well suited to large bodies of water, as bays and open roadsteads.

The device shown, submitted to us by Mr. Jesse W. Reno of New York city, appears to have considerable merit, and would be useful in discouraging submarine attack upon ships passing through extensive bodies of water. The plan is to drop overboard from a small cruiser several hundred of these "catchers" and leave them free to float back and forth with the current. It would be impossible for the enemy to locate them from the conning tower of a submarine, and therefore their presence in such waters would exert a powerful moral influence to prevent the free access of this terrible engine of destruction.

There can be little doubt that a submarine will be put out of commission if it enters, or even strikes a glancing blow against, the submerged ring of the "catcher." This ring, made of light gas pipe or angle iron, is 24 feet in diameter, and is suspended freely by chain to a float which is nearly submerged. Attached to the ring are eight $8 / 4$-inch ropes about 100 feet long with looped ends. The ropes are continuous in pairs and the attachment to the ring is such that it will easily break away and thus permit about 200 feet of rope to wrap around the propeller blades and shaft when the loop is caught nasmuch as all submarines have twin propellers, located at a considerable distance from each side of the keel, the chance that both propellers will be simultaneouly entangled in the trailing ropes is almost certain. The action of twin screws is to cause a powerful insweep of the water currents some distance forward of the stern, which would aid in bringing the ropes in contact with the blades. The "catcher" would have little or no effect upon the ordinary ship, the bow of which, if coming in contact with it, would not engage; in fact, the bow wave would probably push the "catcher" to one to drift .astern. Assuming that a submarine has been caught in the manner described, her distress and location can be signaled by a simple device also invented by Mr. Reno, which will be clear from the following description.

A slack wire or lanyard is strung from the lower edge of the "catcher" ring and continued through a hole in the upper edge of the float. The fleat is provided with a conical hole through which the lanyard is passed. leading to a Coston signal flare contained in the upper end. As the submarine enters the ring it pull the lanyard, setting off a delayed action fuse which will flre the flare, say one minute later, thus giving time for entanglement of the rope with the screws. The Coston signal can also. be supplied with a substance producing a dense brown smoke visible for ten miles in daylight. A day and night signal of this character would enable a small cruiser or torpedo boat to capture or sink a submarine whose propellers were entangled and could not be operated.

The Interstate Commerce Commission and the Shipment of Natural Gas Gasoline

$I^{N}$ the flnal rules of the Interstate Commerce Com$l_{\text {mission regarding the shipment of natural gas gaso }}$ line it is suggestively stated that the commission has not deemed it best "at this time" to prohibit the use of good wooden barrels in shipping inflammable liquids with a flash point below 20 deg. Fahr. (-7 deg. Cent.), while requiring that liquefied petroleum gas must be shipped in metal barrels, drums or tank cars of a certain specification. We say suggestively stated, because the tendency appears to be toward the meta container exclusively and inventors or manufacturers of such containers or those contemplating such manufacture mas well consider the possibility of improveoduct ening or improving the product itself or the process of its manufacture.

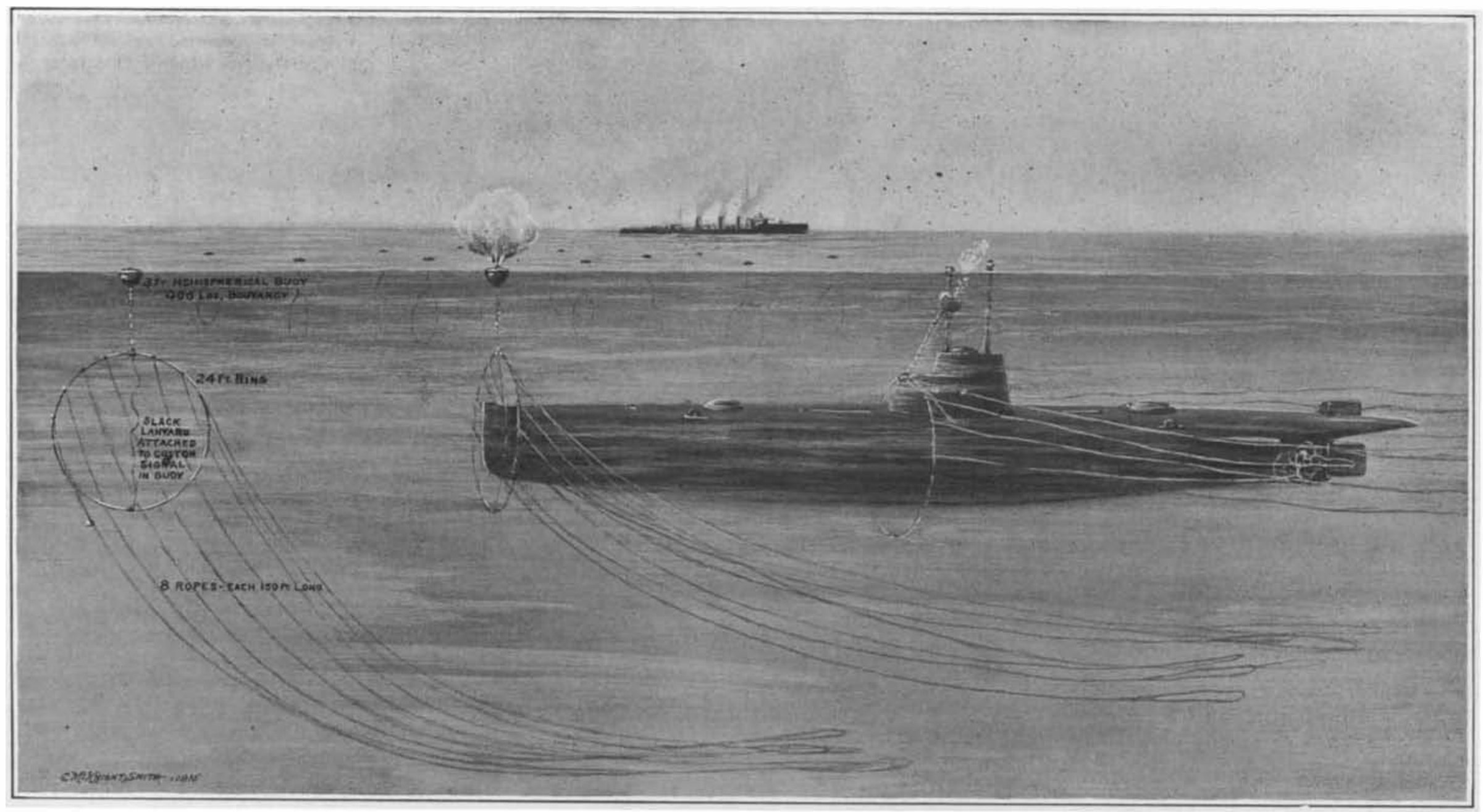

